\title{
Fluorescent in situ hybridization as a screening test for HER2 amplification in G2 and G3 breast cancers of lobular and ductal histotype and metastases
}

\begin{abstract}
ISABELLA CASTELLANO ${ }^{1}$, ANNA SAPINO ${ }^{1}$, RICCARDO ARISIO ${ }^{2}$, GIUSEPPE VIALE ${ }^{3}$, GIANNI BUSSOLATI ${ }^{1}$, ROBERTO BANDELLONI ${ }^{4}$, GAETANO BARRESI $^{5}$, ALESSANDRA BERSIGA $^{6}$, CESARE BORDI $^{7}$, GERARDO BOTTI $^{8}$, FABIA COSIMI $^{9}$, EMANUELE D'AMORE $^{10}$, CLAUDIO DOGLIONI $^{11}$, ANTONIO MARCHETTI ${ }^{12}$, OSCAR NAPPI ${ }^{13}$, FRANCESCO ROMEO ${ }^{14}$, MASSIMO RONCALLI $^{15}$, ROSA RUSSO $^{16}$, ALFREDO SANTINELLI ${ }^{17}$, LUIGI GIUSTO SPAGNOLI ${ }^{18}$, FRANCESCO TANDA $^{19}$, PAOLO TRICOMI $^{20}$, GIANPAOLO TRENTINI ${ }^{21}$, FABRIZIO ZANCONATI ${ }^{22}$ and MONICA IURLARO ${ }^{23}$

${ }^{1}$ Department of Biomedical Sciences and Human Oncology, University of Turin; ${ }^{2}$ Department of Pathology, Sant'Anna Hospital, Torino; ${ }^{3}$ Division of Pathology and Laboratory Medicine, European Institute of Oncology, Milan; ${ }^{4}$ Division of Pathology, Galliera Hospital, Genoa; ${ }^{5}$ Department of Human Pathology, University of Messina, 'Policlinico G. Martino', Messina; ${ }^{6}$ Breast Cancer Unit, Azienda Ospedaliera Istituti Ospitalieri, Cremona; ${ }^{7}$ Department of Pathology and Laboratory Medicine, University of Parma, Parma; ${ }^{8}$ Department of Pathology Fondazione G. Pascale National Tumor Institute, Naples; ${ }^{9}$ Department of Pathology, Ospedali Riuniti, Novi Ligure; ${ }^{10}$ Department of Pathology, Ospedale Civile, Vicenza; ${ }^{11}$ Division of Pathology, H. San Raffaele Scientific Institute, Milan; ${ }^{12}$ Division of Medical Pathology, U.O. Anatomia Patologica, Ospedale Civile di Chieti, Chieti; ${ }^{13}$ Department of Pathology, Anatomia ed Istologia Patologica, Ospedale Cardarelli, Naples; ${ }^{14}$ Department of Human Pathology, Annunziata Hospital, Cosenza;

${ }^{15}$ Department of Pathology, University of Milan School of Medicine and IRCCS Humanitas Clinical Institute, Milan;

${ }^{16}$ Department of Human Pathology, S. Giovanni di Dio e Ruggi d'Aragona Hospital, Salerno; ${ }^{17}$ Institute of Pathology, Polytechnic University of Marche Region, Ancona; ${ }^{18}$ Institute of Anatomic Pathology, Tor Vergata University, Rome; ${ }^{19}$ Institutes of Anatomic Pathology and Histopathology, University of Sassari, Sassari; ${ }^{20}$ Department of Human Pathology, Alessandro Manzoni Hospital, Lecco; ${ }^{21}$ Department of Pathologic Anatomy and Medical Genetics, Section of Pathologic Anatomy, University of Modena and Reggio Emilia, Modena; ${ }^{22}$ Department of Clinical Sciences - Azienda OspedalieroUniversitaria Ospedali Riuniti - University of Trieste, Trieste; ${ }^{23}$ Department of Medical Affairs, Roche, Monza, Italy
\end{abstract}

Received November 27, 2007; Accepted January 9, 2008

\begin{abstract}
The aim of the present study was to evaluate the effectiveness of fluorescence in situ hybridisation (FISH), as a screening test, in moderately- (G2) or poorly- (G3) differentiated breast cancers of the ductal (IDC) and lobular (ILC) histotypes and distant metastases. HER2 FISH was performed on 486 G2 and 477 G3 both of IDC and ILC histotypes and in 241 metastases. A significant difference in
\end{abstract}

Correspondence to: Dr Anna Sapino, Department of Biomedical Sciences and Human Oncology, Via Santena 7, 10126 Turin, Torino, Italy

E-mail: anna.sapino@unito.it

Key words: breast, cancer, effectiveness, fluorescence in situ hybridisation, HER2, metastases the HER2 amplification was observed between G2 (14.8\%) and G3 (31.9\%), with no difference according to the histotype. However, the rate of amplification increased to $36 \%$ in the $\mathrm{G} 2$ /hormone receptor-negative cases as compared to $10.6 \%$ in the $\mathrm{G} 2 /$ receptor-positive cases $(\mathrm{p}<0.0001)$. HER2 was amplified in $17 \%$ of metastases with some differences depending on the location. These data suggest that the HER2 FISH analysis may be an effective screening test in breast cancer metastases and G3 tumors, irrespective of the hormone receptor status or presence of lymphovascular invasion.

\section{Introduction}

HER2 is a transmembrane tyrosine kinase of the epidermal growth factor receptor family encoded by the HER 2 oncogene. Since the first publication on HER2 overexpression in breast cancer (1), hundreds of studies have demonstrated the importance of this growth factor in breast cancer prognosis and treatment (2-4). The HER2 status should be incorporated into clinical decision making, by reporting either the results of the 
receptor protein overexpression by immunohistochemistry (IHC) or gene amplification by in situ hybridization (ISH) procedures. Some authors report a high level of correlation between IHC and ISH assays, the latter considering fluorescent (FISH) and chromogenic (CISH) methods (5). However, FISH is more predictive than IHC in determining the response to trastuzumab (6-10). Consequently, FISH has been used to confirm some or all positive IHC results (11). Recently, an expert panel of the American Society of Clinical Oncology and the College of American Pathologists (ASCO/CAP) recommended that the 'HER2 status should be determined for all invasive breast cancer' and suggested either HER2-validated IHC or FISH assay as the first test for HER2 assessment $(12,13)$.

The cost involved for the different tests is also important. FISH testing is more costly than IHC. It is likely that the use of HER2 FISH as a screening test would result in a relevant cost increase. Elkin et al (14) reported on an analysis on the cost-effectiveness of alternative HER2 testing and trastuzumab treatment strategies, and concluded that the additional costs associated with FISH should be weighed against the increasing accuracy of FISH testing, as compared to IHC. In other words, because the IHC false positive rate is higher compared to FISH, this would result in cost savings due to the increase in treatment appropriateness. Perhaps it would be worthwhile to use FISH as a screening test when the probability of amplification is higher, and use IHC testing for all other tumors. For example, several studies demonstrated that HER2 amplification is a rare event in low grade or special type cancers. Hoff et al (15) suggest the re-examination of the HER2 amplified tumor be diagnosed as grade 1 or as a lobular carcinoma to exclude the possibility of histopathological misclassification. However, the difference in HER2 amplification between moderately- (G2) or poorly(G3) differentiated breast carcinomas has yet to be fully studied in a similar manner to the significance of the grade of differentiation in lobular carcinoma (classical versus pleomorphic) and HER2 amplification.

Another concern is the study of the HER2 gene in distant metastases. The assessment of HER2 is performed in the primary tumor, even if metastases appear several years later. However, some authors suggest that a possible discordance of HER2 overexpression between primary tumors and metastases should be considered when making treatment decisions (16). As a result, in the present multi-institutional study, we focused on G2 and G3 invasive breast carcinomas of the ductal (IDC) and lobular (ILC) histotypes and distant metastases to validate the effectiveness of FISH as a screening test in this specific subset of patients.

\section{Materials and methods}

Twenty-two Italian pathology laboratories, diagnosing at least 250 breast cancers/year and performing >100 FISH analyses/year, were asked to perform FISH as a first test in invasive primary breast carcinomas, of the ductal and lobular histotypes, graded as G2 and G3 by the Elston and Ellis scoring system (17). A similar analysis was performed on the distant metastases of breast cancer. Cases diagnosed as ILC included tumors that demonstrated a complete lack of duct formation and had typical lobular features. Proven E-cadherin negative pleomorphic lobular carcinomas were also included in the ILC subgroup.

Further collected data were patient age, lymphovascular invasion (LVI) and tumor hormone receptor status (HR).

Fluorescence in situ hybridisation (FISH). A PathVysion HER2/neu probe kit (Vysis Inc., Downers Grove, IL, USA) was used for FISH analysis. Sections were baked overnight at $56^{\circ} \mathrm{C}$, dewaxed in xylene, dehydrated in $99 \%$ ethanol and air-dried. Slides were then pre-treated with Na-thiocyanate at $80^{\circ} \mathrm{C}$ for $30 \mathrm{~min}$ and digested with proteases for $15 \mathrm{~min}$ at $37^{\circ} \mathrm{C}$ and finally hybridized overnight at $37^{\circ} \mathrm{C}$ with the probes (HER2/neu/CEP17 SG probe 35-171060, Vysis Inc.) after DNA denaturation at $72^{\circ} \mathrm{C}$. Slides were washed with post-hybridization buffer at $72^{\circ} \mathrm{C}$, counterstained with 4,6 diamidino-2-phenylindole (DAPI) and mounted and stored in the dark prior to signal enumeration. For FISH analysis, slides were examined with the Olympus BX41 fluorescence microscope equipped with a $100 \mathrm{x}$ oil immersion objective and a triple band pass filter for the simultaneous detection of Spectrum Orange, Spectrum Green and DAPI signals. Areas of optimal tissue digestion and no overlapping nuclei were then selected in each core for counting. Cells (40-60) were counted for each case. We considered cases with a FISH ratio (HER2 gene signals to chromosome 17 signals) of $\geq 2.2$ as amplified.

Statistical analysis. To define the correlation between HER2 amplification and each of the potential predictors of histotype (IDC versus ILC), grade (2 versus 3), LVI (absent versus present), HR status (positive versus negative) and age (as a continuous variable and 10-year age steps), a univariate analysis for categorical data was performed using the Pearson Chi-square test with continuity correction and odds ratios. The significance levels were set at $\mathrm{p}<0.05$. All tests were two-sided. A multivariate analysis was performed using binomial logistic regression with stepwise regression (reverse selection). The analyses were performed using SPSS for Windows (v. 13.0).

\section{Results}

FISH was successful in 963 primary breast cancers and in 241 distant metastases. HER2 amplification was observed in $23.2 \%$ of the primary tumors. HR status and LVI were known in 889 and 874 primary cancers, respectively, because FISH testing was performed in primary tumors as part of the hospital service.

In the primary tumors, the univariate analysis showed statistically significant differences in the frequencies of amplification between G2 (14.8\%) versus G3 (31.9\%) $(\mathrm{p}<0.0001)$, absence $(16.8 \%)$ versus the presence of LVI $(28.5 \%)(\mathrm{p}<0.0001)$ and HR positive $(17.3 \%)$ versus negative $(39.6 \%)(\mathrm{p}<0.0001)$. Although IDC showed a higher percentage of the HER2 amplification (23.9\%), no significant difference was observed with ILC $(16 \%)(\mathrm{p}<0.1000)$ (Table I). Specifically, 68 out of 440 (15.5\%) G2 IDC were amplified versus 4 out of $46(8.7 \%)$ G2 ILC and 143 out of $442(32.4 \%)$ G3 IDC versus 9 out of 35 (25.7\%) G3 ILC. A younger age 
Table I. The correlation of the HER2 amplification with histopathological predictors.

\begin{tabular}{lcccc}
\hline & $\begin{array}{c}\text { No. of } \\
\text { cases }\end{array}$ & $\begin{array}{c}\text { FISH not } \\
\text { amplified } \\
(\%)\end{array}$ & $\begin{array}{c}\text { FISH } \\
\text { amplified } \\
(\%)\end{array}$ & P-value \\
\hline IDC $^{\text {a }}$ & 882 & $671(76.1)$ & $211(23.9)$ & 0.1000 \\
ILC $^{\text {b }}$ & 81 & $68(84.0)$ & $13(16.0)$ & \\
Grade 2 & 486 & $414(85.2)$ & $72(14.8)$ & 0.0000 \\
Grade 3 & 477 & $325(68.1)$ & $152(31.9)$ & \\
LVI $^{\mathrm{c}}$ & & & & \\
Absent & 488 & $406(83.2)$ & $82(16.8)$ & 0.0000 \\
Present & 386 & $276(71.5)$ & $110(28.5)$ & \\
HR status & & & & \\
Positive & 677 & $560(82.7)$ & $117(17.3)$ & 0.0000 \\
Negative & 212 & $128(60.4)$ & $84(39.6)$ & \\
\hline
\end{tabular}

aIDC, invasive ductal carcinoma; ' ILC, invasive lobular carcinoma; 'LVI, lymphovascular invasion and ${ }^{\mathrm{d}} \mathrm{HR}$ status, hormonal receptor status.

Table II. The multivariate analysis of HER2 amplification. ${ }^{\mathrm{a}}$

\begin{tabular}{lccc}
\hline & OR & $95 \%$ CI & P-value \\
\hline $\begin{array}{l}\text { Histotype } \\
\text { IDC }^{\mathrm{b}} \text { vs. ILC }\end{array}$ & 1.212746 & $0.6518421-2.256301$ & 0.543 \\
Grade (2 vs. 3) & 0.438 & $0.300-0.639$ & $<0.0001$ \\
LVI $^{\mathrm{d}}$ & 0.531 & $0.371-0.760$ & $<0.0010$ \\
$\begin{array}{l}\text { (Absent vs. present) } \\
\text { HR status }\end{array}$ & & & \\
(Positive vs. negative) & & $0.266-0.575$ & $<0.0001$ \\
\hline
\end{tabular}

${ }^{\mathrm{a}}$ Model is based on 807 observations. bIDC, invasive ductal carcinoma; 'ILC, invasive lobular carcinoma; ${ }^{\mathrm{d}} \mathrm{LVI}$, lymphovascular invasion and eHR status, hormonal receptor status.

was significantly correlated with HER2 amplification (OR per one-year increase of age: $0.9837791,95 \% \mathrm{CI}=0.972823$ $0.9948585, \mathrm{p}=0.004$ after 904 observations).

Multivariate analysis confirmed that grade, LVI and HR status were the only independent predictors of HER2 gene amplification (Table II). When we considered the G2/HR positive carcinomas, the amplification rate was 10.6 versus $36.1 \%$ of the $\mathrm{G} 2 / \mathrm{HR}$ negative cases $(\mathrm{p}<0.0001)$. Additionally, G2/LVI absent was amplified in $9.5 \%$ of cases versus $20.9 \%$ of $\mathrm{G} 2 / \mathrm{LVI}$ present cases ( $\mathrm{p}<0.001$ ). In $\mathrm{G} 3 / \mathrm{HR}$ positive cases, $26.2 \%$ were $H E R 2$ amplified versus $41.1 \%$ of G3/HR negative $(\mathrm{p}<0.001)$ cases, while the difference in amplification was not significant with or without LVI (34.1 versus $26.3 \%$, $\mathrm{p}<0.0700$ ) (Table III).

Metastases were amplified in 42 out of 241 (17.4\%) cases. In 41 cases, the site of the metastases was unknown. HER2
Table III. The significance of hormonal receptor status and lymphovascular invasion in HER2 amplification of Grades 2 and 3 breast carcinomas.

\begin{tabular}{lccc}
\hline & $\begin{array}{c}\text { FISH not } \\
\text { amplified } \\
(\%)\end{array}$ & $\begin{array}{c}\text { FISH } \\
\text { amplified } \\
(\%)\end{array}$ & P-value \\
\hline Grade 2 & & & \\
HR $^{\text {a }}$ positive & $346(89.4)$ & $41(10.6)$ & 0.0001 \\
HR negative & $39(63.9)$ & $22(36.1)$ & \\
Grade 3 & & & \\
HR positive & $214(73.8)$ & $76(26.2)$ & 0.0010 \\
HR negative & $89(58.9)$ & $62(41.1)$ & \\
Grade 2 & & & 0.0010 \\
LVI ${ }^{\mathrm{b}}$ absent & $249(90.5)$ & $26(9.50)$ & \\
LVI present & $129(79.1)$ & $34(20.9)$ & \\
Grade 3 & & & 0.0700 \\
LVI absent & $157(73.7)$ & $56(26.3)$ & \\
LVI present & $147(65.9)$ & $76(34.1)$ & \\
\hline
\end{tabular}

${ }^{\mathrm{a}} \mathrm{HR}$, hormonal receptor status and ${ }^{\mathrm{b}} \mathrm{LVI}$, lymphovascular invasion.

Table IV. Sites of metastases and HER2 amplification.

\begin{tabular}{lrrr}
\hline Sites & $\begin{array}{r}\text { No. of } \\
\text { cases }\end{array}$ & $\begin{array}{r}\text { FISH not } \\
\text { amplified } \\
(\%)\end{array}$ & $\begin{array}{c}\text { FISH } \\
\text { amplified } \\
(\%)\end{array}$ \\
\hline Lymph nodes & 56 & $46(82)$ & $10(18)$ \\
Bone & 4 & $3(75)$ & $1(25)$ \\
Central nervous system & 6 & $6(100)$ & $0(0)$ \\
Liver & 37 & $29(78.4)$ & $8(21.6)$ \\
Skin & 64 & $55(86)$ & $9(14)$ \\
Lung/pleura & 33 & $29(88)$ & $4(12)$ \\
Other & 41 & $31(76)$ & $10(24)$ \\
\hline
\end{tabular}

amplification was higher $(21.6 \%)$ in liver metastases relative to skin (14\%) and lung lesions (12\%). The site of lymph node metastases was unknown, however, 10 out of $56(18 \%)$ cases were amplified. Four cases of bone metastases were tested, only one $(25 \%)$ was amplified. Notably, none of the 6 central nervous system (CNS) metastasis cases were amplified (Table IV).

\section{Discussion}

HER2 amplification in different histological types and grades of female breast cancer has traditionally been a subject of interest. Some studies have shown that HER2 amplification or overexpression were significantly more likely in IDC than ILC and in higher grade G3 IDC than in lower grade G1/G2 IDC $(15,18-20)$. However, while the percentage of amplified G1 tumors ranged from 1 to $4 \%, \mathrm{G} 2$ tumors ranged from 9 to $18 \%$ 
(15-21). Taking these data into account, we focused on G2 and G3 invasive carcinomas of the ductal and lobular histotypes and showed that grade significantly correlates with $H E R 2$ amplification. Few studies have evaluated the frequency of HER2 amplification in the ILC of grade 2 or 3 , the latter corresponding to the majority of cases for the pleomorphic variant (22). Most cases of ILC, in their classic variant, are positive for estrogen and progesterone receptors and negative for HER2. On the other hand, 53 to $81 \%$ of pleomorphic lobular carcinomas have been described as HER2 positive $(23,24)$. In our series, $16 \%$ of G2/G3 ILC were amplified. This result reinforces the conclusion drawn by Arpino et al (25) that 'management decisions should be based on individual patient and tumor biological characteristics, and not on lobular histology'. While it has been suggested that HER2 gene amplification is more common in younger patients (19), multivariate analysis failed to confirm a significant relationship between $H E R 2$ gene amplification and patient age in our study.

Recent studies have reported HER2 amplification in 18$20 \%$ of samples tested with FISH $(26,27)$. The present study focused on $\mathrm{G} 2 / \mathrm{G} 3$ breast carcinomas and the overall percentage of amplification was $23 \%$ and $30 \%$ when G3 carcinomas were considered. These data indirectly confirm the low impact G1 tumors have on the rate of HER2 gene amplification. Conversely, $\sim 15 \%$ of moderately-differentiated G2 breast carcinomas may be amplified. Other studies have delved deeper into analysing the features related to HER2 amplification and predicted the HER2 status of breast cancer from basic histopathology and immunophenotypical data $(19,20,28)$, such as LVI and HR status. Taucher et al (18) proposed a scoring system to determine the probability of $H E R 2$ positivity (diagnostic instrument for the validation of $H E R 2 /$ neu, DIVER score). This scoring system was determined by prognostic markers that exhibit the strongest correlation with HER2 status, namely estrogen and progesterone receptors and tumor grade. They concluded that in a subgroup of patients demonstrating hormone-responsive and G1/G2 tumors, the likelihood of HER2 overexpression was very small. We have shown that in the categories of G2/G3 breast cancers, HR status was significantly correlated with HER2 gene status as well. Only $17 \%$ of breast carcinomas expressing HR show HER2 amplification versus $40 \%$ of HR negative carcinomas. Moreover, G2/HR negative breast cancers have an amplification rate similar to those of G3 breast carcinomas. In contrast to the results of Crowe et al (19), LVI was determined to be another significant independent variable in our multivariate analysis. However, LVI is not always reproducible even among expert pathologists (29), while the HR status, in particular estrogen receptor expression, is an all or nothing phenomenon that is more easily reproduced on histological slides (30). Finally, Gong et al (16) suggested that the HER2 gene does not appear to be linked directly to tumor dissemination. Our data confirm this hypothesis since only $17 \%$ of breast cancer metastases show HER2 amplification, while we expected amplification rates of at least $23 \%$. Notably, the results of HER2 gene analysis on CNS metastases in our series indicate the need for larger studies to elucidate whether trastuzumab resistance in CNS metastases is a true phenomenon or a consequence of the absence of HER2 amplification (31). Eligibility for trastuzumab therapy in advanced breast cancer patients warrants the use of FISH as a screening test whenever possible, particularly considering that samples from FNA of the metastatic lesion are frequently the only specimens available for diagnosis. It is well known that more variability is found in the IHC results compared with the FISH results on FNA samples, and scoring the FISH signals in such small tissue samples is more objective than scoring IHC staining $(32,33)$.

In conclusion, considering the overall logistical difficulties as well as the accuracy, time and cost for the double testing of HER2 (IHC/FISH), gene analysis may be an efficient and useful approach for HER2 screening of breast cancer metastases and G3 tumors, particularly for laboratories running a large number of breast cancer surgical specimens, where the pathological experience would guarantee a correct grading of the tumor. For all the non-G3 tumors, the rational algorithm for HER2 testing would be to perform IHC first, followed by FISH to validate equivocal IHC results (12).

\section{Acknowledgements}

Supported by grants from Compagnia di San Paolo special project 'Oncology', Ministero Istruzione Università e Ricerca (MIUR) Progetti di Ricerca di Interesse Nazionale (PRIN) 2005, Ministero dell' Università della Ricerca Scientifica e Tecnologica (MURST) (ex 60\%) and Fondazione Cassa di Risparmio di Torino (CRT) for financial support. Regione Piemonte Comitato Interministeriale per la Programmazione Economica (CIPE) 2004 provided valuable financial contributions.

\section{References}

1. Slamon DJ, Clark GM, Wong SG, Levin WJ, Ullrich A and McGuire WL: Human breast cancer: correlation of relapse and survival with amplification of the HER-2/neu oncogene. Science 235: 177-182, 1987.

2. Press MF, Pike M, Chazin VR, et al: Her-2/neu expression in node-negative breast cancer: direct tissue quantitation by computerized image analysis and association of overexpression with increased risk of recurrent disease. Cancer Res 53: 4960-4970, 1993.

3. Press MF, Bernstein L, Thomas PA, et al: HER-2/neu gene amplification characterized by fluorescence in situ hybridization: poor prognosis in node-negative breast carcinomas. J Clin Oncol 15: 2894-2904, 1997.

4. Yamauchi H, Stearns V and Hayes DF: When is a tumor marker ready for prime time? A case study of c-erbB-2 as a predictive factor in breast cancer. J Clin Oncol 19: 2334-2356, 2001.

5. Di Palma S, Collins N, Faulkes C, et al: Chromogenic in situ hybridisation (CISH) should be an accepted method in the routine diagnostic evaluation of HER2 status in breast cancer. J Clin Pathol 60: 1067-1068, 2007.

6. Dybdal N, Leiberman G, Anderson S, et al: Determination of HER2 gene amplification by fluorescence in situ hybridization and concordance with the clinical trials immunohistochemical assay in women with metastatic breast cancer evaluated for treatment with trastuzumab. Breast Cancer Res Treat 93: 3-11, 2005.

7. Slamon DJ, Leyland-Jones B, Shak S, et al: Use of chemotherapy plus a monoclonal antibody against HER2 for metastatic breast cancer that overexpresses HER2. N Engl J Med 344: 783-792, 2001.

8. Cobleigh MA, Vogel CL, Tripathy D, et al: Multinational study of the efficacy and safety of humanized anti-HER2 monoclonal antibody in women who have HER2-overexpressing metastatic breast cancer that has progressed after chemotherapy for metastatic disease. J Clin Oncol 17: 2639-2648, 1999. 
9. Vogel CL, Cobleigh MA, Tripathy D, et al: Efficacy and safety of trastuzumab as a single agent in first-line treatment of HER2overexpressing metastatic breast cancer. J Clin Oncol 20: 719-726, 2002.

10. Joensuu H, Kellokumpu-Lehtinen PL, Bono P, et al: Adjuvant docetaxel or vinorelbine with or without trastuzumab for breast cancer. N Engl J Med 354: 809-820, 2006.

11. Yaziji $\mathrm{H}$ and Gown AM: Testing for HER-2/neu in breast cancer: is fluorescence in situ hybridization superior in predicting outcome? Adv Anat Pathol 9: 338-344, 2002.

12. Wolff AC, Hammond ME, Schwartz JN, et al: American Society of Clinical Oncology/College of American Pathologists guideline recommendations for human epidermal growth factor receptor 2 testing in breast cancer. J Clin Oncol 25: 118-145, 2007.

13. Wolff AC, Hammond ME, Schwartz JN, et al: American Society of Clinical Oncology/College of American Pathologists guideline recommendations for human epidermal growth factor receptor 2 testing in breast cancer. Arch Pathol Lab Med 131: 18,2007

14. Elkin EB, Weinstein MC, Winer EP, Kuntz KM, Schnitt SJ and Weeks JC: HER-2 testing and trastuzumab therapy for metastatic breast cancer: a cost-effectiveness analysis. J Clin Oncol 22: 854-863, 2004.

15. Hoff ER, Tubbs RR, Myles JL and Procop GW: HER2/neu amplification in breast cancer: stratification by tumor type and grade. Am J Clin Pathol 117: 916-921, 2002.

16. Gong Y, Booser DJ and Sneige N: Comparison of HER-2 status determined by fluorescence in situ hybridization in primary and metastatic breast carcinoma. Cancer 103: 1763-1769, 2005.

17. Elston CW and Ellis IO: Pathological prognostic factors in breast cancer. I. The value of histological grade in breast cancer: experience from a large study with long-term follow-up. Histopathology 19: 403-410, 1991.

18. Taucher S, Rudas M, Mader RM, et al: Do we need HER-2/neu testing for all patients with primary breast carcinoma? Cancer 98: 2547-2553, 2003

19. Crowe JP, Patrick RJ, Rybicki LA, et al: A data model to predict HER2 status in breast cancer based on the clinical and pathologic profiles of a large patient population at a single institution. Breast 15: 728-735, 2006

20. Bilous M, Ades C, Armes J, et al: Predicting the HER2 status of breast cancer from basic histopathology data: an analysis of 1500 breast cancers as part of the HER2000 International Study. Breast 12: 92-98, 2003.

21. Lal P, Tan LK and Chen B: Correlation of HER-2 status with estrogen and progesterone receptors and histologic features in 3,655 invasive breast carcinomas. Am J Clin Pathol 123: 541-546, 2005 .
22. Reis-Filho JS, Simpson PT, Jones C, et al: Pleomorphic lobular carcinoma of the breast: role of comprehensive molecular pathology in characterization of an entity. J Pathol 207: 1-13, 2005.

23. Middleton LP, Palacios DM, Bryant BR, Krebs P, Otis CN and Merino MJ: Pleomorphic lobular carcinoma: morphology, immunohistochemistry, and molecular analysis. Am J Surg Pathol 24: 1650-1656, 2000.

24. Frolik D, Caduff R and Varga Z: Pleomorphic lobular carcinoma of the breast: its cell kinetics, expression of oncogenes, and tumor suppressor genes compared with invasive ductal carcinomas and infiltrating lobular carcinomas. Histopathology 39: 503-513, 2001.

25. Arpino G, Bardou VJ, Clark GM and Elledge RM: Infiltrating lobular carcinoma of the breast: tumour characteristics and clinical outcome. Breast Cancer Res 6: R149-R156, 2004.

26. Yaziji H, Goldstein LC, Barry TS, et al: HER-2 testing in breast cancer using parallel tissue-based methods. JAMA 291: 1972-1977, 2004.

27. Owens MA, Horten BC and Da Silva MM: HER2 amplification ratios by fluorescence in situ hybridization and correlation with immunohistochemistry in a cohort of 6556 breast cancer tissues. Clin Breast Cancer 5: 63-69, 2004.

28. Ariga R, Zarif A, Korasick J, Reddy V, Siziopikou K and Gattuso P: Correlation of Her-2/neu gene amplification with other prognostic and predictive factors in female breast carcinoma. Breast J 11: 278-280, 2005.

29. Sloane JP, Amendoeira I, Apostolikas N, et al: Consistency achieved by 23 European pathologists from 12 countries in diagnosing breast disease and reporting prognostic features of carcinomas. European Commission Working Group on Breast Screening Pathology. Virchows Arch 434: 3-10, 1999.

30. Nadji M, Gomez-Fernandez C, Ganjei-Azar P and Morales AR: Immunohistochemistry of estrogen and progesterone receptors reconsidered: experience with 5,993 breast cancers. Am J Clin Pathol 123: 21-27, 2005

31. Montemurro F and Aglietta M: The risk of central nervous system metastases after trastuzumab therapy in patients with breast carcinoma. Cancer 103: 1314-1315, 2005.

32. Beatty BG, Bryant R, Wang W, Ashikaga T, Gibson PC, Leiman G and Weaver DL: HER-2/neu detection in fine-needle aspirates of breast cancer: fluorescence in situ hybridization and immunocytochemical analysis. Am J Clin Pathol 122: 246-255, 2004.

33. Daniele L, Macri L, Schena M, et al: Predicting gefitinib responsiveness in lung cancer by fluorescence in situ hybridization/chromogenic in situ hybridization analysis of EGFR and HER2 in biopsy and cytology specimens. Mol Cancer Ther 6: 1223-1229, 2007. 